\title{
DEEP DYSPAREUNIA: REVIEW OF PATHOPHYSIOLOGY AND PROPOSED FUTURE RESEARCH PRIORITIES
}

Natasha Orr, MSc ${ }^{\mathrm{a}, \mathrm{c}, \mathrm{d},{ }^{*}}$, Kate Wahl, BSc${ }^{\mathrm{a}-\mathrm{d}, *}$, Angela Joannou ${ }^{\mathrm{c}}$, Dee Hartmann, PT, DPT ${ }^{\mathrm{d}}$, Lisa Valle, $\mathrm{DO}^{\mathrm{e}}$, Paul Yong, MD, PhD ${ }^{\mathrm{a}, \mathrm{c}, \mathrm{d}}$ and ISSWH Special Interest Group on Sexual Pain ${ }^{\mathrm{h}}$

*Contributed equally to the work

${ }^{\mathrm{a}}$ Department of Obstetrics and Gynecology and ${ }^{\mathrm{b}}$ School of Population and Public Health, University of British Columbia; ${ }^{\mathrm{B}} \mathrm{BC}$ Women's Centre for Pelvic Pain and Endometriosis and ${ }^{\mathrm{d}}$ Women's Health Research Institute, Vancouver, British Columbia, Canada

${ }^{\mathrm{d}}$ Dee Hartman Physical Therapy, Chicago, Illinois, United States

'Oasis Women’s Sexual Function Center, Santa Monica, California, United States

${ }^{\mathrm{h}}$ ISSWSH Special Interest Group on Sexual Pain: Corey Babb, DO (Oklahoma State University, Stillwater, Oklahoma, United States), Catherine Cramer, PT, MPT (Women First Rehab, Woodstock, Georgia, United States), Susan Kellog-Spadt, PhD, CRNP (Drexel University, Philadelphia, Pennsylvania, United States), Roberta I Renzelli-Cain, DO (West Virginia University School of Medicine, Morgantown, West Virginia, United States)

October $16^{\text {th }} 2018$

Disclosures: None.

Acknowledgements: PY is supported by the Health Professional Investigator Award of the Michael Smith Foundation for Health Research.

Corresponding author:

Paul Yong, MD, PhD, FRCSC

Assistant Professor, Department of Obstetrics and Gynecology

University of British Columbia;

BC Women’s Center for Pelvic Pain and Endometriosis, F2 - 4500 Oak Street, Vancouver, British Columbia

Canada V6H 3N1

Tel: 604-875-2534; Fax: 604-875-2569; Email: Paul.Yong@vch.ca 


\title{
DEEP DYSPAREUNIA: REVIEW OF PATHOPHYSIOLOGY AND PROPOSED FUTURE RESEARCH PRIORITIES
}

\begin{abstract}
$\underline{\text { Abstract }}$
Introduction: Dyspareunia has been traditionally divided into superficial (introital) dyspareunia and deep dyspareunia (pain with deep penetration). While deep dyspareunia can co-exist with a variety of conditions, recent work in endometriosis has demonstrated that co-existence does not necessarily imply causation. Therefore, a re-consideration of the literature is required to clarify the pathophysiology of deep dyspareunia.
\end{abstract}

Aims: To review the pathophysiology of deep dyspareunia, and to propose future research priorities.

Methods: Narrative review after appraisal of published frameworks and literature search with the terms (dyspareunia AND endometriosis), (dyspareunia AND deep), (dyspareunia AND (pathophysiology OR etiology)).

Main Outcome Variable: Deep dyspareunia (present/absent or along a pain severity scale).

Results: Potential etiologies for deep dyspareunia include gynecological, urological, gastrointestinal, nervous system, psychological, and musculoskeletal system related. These etiologies can be classified according to anatomic mechanism (contact with a tender pouch of Douglas, uterus-cervix, bladder, or pelvic floor, with deep penetration). They can also be stratified into four categories (as previously proposed for endometriosis specifically), which can be utilized to personalize management: Type I (primarily gynecologic), Type II (nongynecologic comorbid conditions), Type III (central sensitization and genito-pelvic pain 
penetration disorder), and Type IV (mixed). Sociocultural and genetic factors and sexual response may also be important for deep dyspareunia.

Conclusion: We propose the following eight research priorities for deep dyspareunia: 1) development of deep dyspareunia measurement tools; 2) focus on the population who are avoiding intercourse due to deep dyspareunia; 3) clarification of the role of non-gynecologic comorbidities in the generation of deep dyspareunia; 4) addressing of ethnic and other sociocultural factors; 5) initiation of clinical trials with adequate power for deep dyspareunia outcomes; 6) inclusion of partner variables; 7) elucidation of pathways between psychological factors and deep dyspareunia; and 8) empirical validation of personalized approaches to deep dyspareunia.

\section{$\underline{\text { Keywords }}$}

Deep dyspareunia; Superficial dyspareunia; Pathophysiology; Treatment

\section{Introduction}

Although sex should be a satisfying experience, the sad truth is that for too many women it is painful. Although the prevalence of sexual pain varies depending on study population and methods, one review showed that as many as $61 \%$ of women experience pain during sex in their lifetime [1]. This sexual pain can have a profound effect on a woman, her psychological wellbeing, relationships, and quality of life [2, 3]. Despite the wide spread prevalence of painful sex 
among women, there is a need for more research to examine how and why this experience is so common.

Dyspareunia can be considered superficial (pain at the vaginal introitus with initial penetration) or deep (occurring within the pelvis in deep penetration) during penetrative intercourse. The etiology of superficial and deep dyspareunia are often different, with provoked vestibulodynia, pelvic floor dysfunction, vulvar dermatoses, and genitourinary syndrome of menopause being common causes of superficial pain. Similar to superficial dyspareunia, the causes of deep dyspareunia are heterogeneous and enigmatic. It is difficult to draw conclusions about deep dyspareunia from the current body literature because this type of pain is infrequently distinguished from superficial pain and is rarely a primary research outcome.

Deep dyspareunia is known to be important symptom in endometriosis and has been subject to some research [4]; however there is a need to consider other contributors to deep dyspareunia as well. In particular, it is important to note that simply because a condition co-exists with deep dyspareunia in the patient, does not necessarily mean that the condition is directly causing the sexual pain. The purpose of this review is therefore to re-consider the current evidence regarding the pathophysiology of deep dyspareunia within an anatomic model and a previously proposed framework for endometriosis specifically [5]. The framework uses pain mechanisms and the DSM-V concept of genito-pelvic pain penetration disorder to define four types of deep dyspareunia: gynecological (Type I), comorbid conditions (Type II), central sensitization and genito-pelvic pain penetration disorder (Type III), and mixed (Type IV) [5]. Furthermore, we aim to define a set of research priorities to guide the investigation of deep dyspareunia in the future. 


\section{$\underline{\text { Methods }}$}

For this narrative review, we examined both textbook frameworks for deep dyspareunia (e.g. [6]) as well as the published literature through PubMed search using the terms (endometriosis AND dyspareunia) OR (dyspareunia AND deep) OR (dyspareunia AND (pathophysiology OR etiology)). We did not include obvious anatomic causes of sexual pain, such as large fibroids or large ovarian cysts, which are dealt with surgically and are uncontroversial. In the Results, we specify “deep dyspareunia” when it was explicitly addressed in the cited study, but use the term “dyspareunia” when the study did not differentiate deep and superficial dyspareunia.

\section{$\underline{\text { Results }}$}

\section{ANATOMIC CONSIDERATIONS}

It has been proposed that direct contact with a variety of tender pelvic structures at the apex of the vagina during deep penetration may be lead to deep dyspareunia [5]. These structures include: the pouch of Douglas/cul-de-sac, the cervix-uterus, the pelvic floor, and the bladder base [5]. This anatomic model will be considered below, under each of the four proposed Types of deep dyspareunia.

TYPE I: PRIMARY GYNECOLOGICAL CONDITIONS

\section{Extrauterine (e.g. pouch of Douglas)}

Endometriosis 
Endometriosis is a common gynecologic condition characterized by ectopic uterine tissue that is classified as superficial peritoneal endometriosis ( $<5 \mathrm{~mm}$ invasion), deep infiltrating endometriosis ( $\geq 5 \mathrm{~mm}$ invasion), or ovarian endometrioma (cysts). Approximately one in 10 reproductive-aged women are affected by endometriosis and half of these experience moderate to severe deep dyspareunia [7].

Deep infiltrating endometriotic lesions in the pouch of Douglas have been associated with deep dyspareunia likely because this area is contacted during penetration [8, 9]. Pelvic adhesions are common in endometriosis, especially with deep infiltrating endometriosis, and may also contribute to deep dyspareunia [10, 11]. With respect to superficial peritoneal endometriosis, one study showed that superficial endometriotic lesions of the pouch of Douglas in women with deep dyspareunia had increased density of nerve bundles, as well as elevated immune-intensity of nerve growth factor and its TrkA receptor, compared to patients with endometriotic lesions of the same anatomic location but without deep dyspareunia [12, 13]. These findings suggest that local neurogenesis around endometriosis may also contribute to pain with intercourse [12, 13]. Local inflammation via cyclooxygenase-2 (COX-2)-prostaglandin E2 (PGE2)-estrogen and other inflammatory positive feedback loops may also contribute to deep dyspareunia in endometriosis [14]. For example, in another study of women with deep infiltrating endometriosis of the rectosigmoid colon, transforming growth factor beta (TGF $\beta$ ), interleukin 7 (IL7), and interleukin 15 (IL15) were associated with severity of dyspareunia [15].

As discussed in a previous review on deep dyspareunia in endometriosis specifically, conventional treatments of endometriosis include hormonal suppression of the hypothalamicpituitary-ovarian-uterine axis (with progestins, estrogen-progestins, or GnRH agonists) or surgical excision of lesions [5]. However, placebo-controlled randomized trials for these 
conventional treatments have not shown a difference for the specific outcome of deep dyspareunia [5]. The reason for this may be related to inadequate power in these trials (as sexual pain is a secondary outcome only), or because of the increasing recognition of the multifactorial nature of endometriosis-associated pain that can include comorbid non-gynecologic conditions and central sensitization which require different management strategies (as discussed below). That being said, a placebo-controlled randomized controlled trial for a new oral GnRH antagonist for endometriosis showed a benefit for dyspareunia at higher doses [16], indicating that hormonal therapy may be beneficial in some cases. In addition, although not studied systematically, changes in sexual position that avoid contact with the pouch of Douglas (i.e. the posterior fornix of the vagina) may help reduce deep dyspareunia in the endometriosis population.

\section{Genitourinary Syndrome of Menopause}

Genitourinary syndrome of menopause (GSM) includes symptoms secondary to hypoestrogenism during menopause with respect to the vulva, vagina, and lower urinary tract. Dyspareunia is a symptom of GSM that affects $44 \%$ of naturally or surgically postmenopausal women as well as women who experience estrogen deficiency as a result of chemotherapy or hormonal suppression [17-19]. To our knowledge, research studies on sexual pain in menopause have not distinguished superficial and deep dyspareunia; however, dryness, insufficient lubrication, and thinning of the vaginal epithelium, as well as shortening of the vagina due to diminished elasticity and flexibility, may contribute to deep pain at the vaginal apex such as at the pouch of Douglas [20, 21]. Conventional treatments include vaginal moisturizers, local 
estrogen replacement, and newer hormonal therapies (e.g. prasterone and ospemifene) [22, 23], and although a complete appraisal of the literature of this topic is outside the scope of this review, it would be interesting to determine whether these treatments affect superficial dyspareunia and deep dyspareunia in the same way or differentially.

\section{Iatrogenic}

Shortening of the vagina, with sequelae similar to those of GSM, may occur after gynecological surgery or pelvic radiation [24-27]. Dyspareunia can sometimes arise de novo after hysterectomy; one prospective observational study showed that sexual pain was more common among women treated with vaginal hysterectomy than abdominal hysterectomy, perhaps because of shortening of the vagina in the former procedure $[28,29]$. There is a lack of literature on studies evaluating strategies to manage surgically iatrogenic deep dyspareunia, although possibilities include local estrogen replacement and use of serial vaginal inserts [30-33]. In addition, impaired vaginal elasticity also appears to increase risk of deep dyspareunia following radiotherapy for gynecologic cancer. In a population-based study of women who received pelvic radiation, $40 \%$ reported deep dyspareunia and those with impaired vaginal elasticity were at greater risk of deep dyspareunia than those with normal vaginal elasticity [34].

\section{Pelvic Organ Prolapse}

Pelvic organ prolapse (POP) refers to the descent of the pelvic viscera due to weakness of the pelvic floor that can be described by compartment (anterior or cystocele, posterior or rectocele, 
and apical). In a population-based study, $2.9 \%$ of women were found to have POP on physical examination [35]. The relationship between POP and dyspareunia is controversial; in a retrospective study Burrows et al. [36] found that 35\% of women who had surgery for POP experienced sexual pain, whereas Handa et al. [37] found no association between POP and dyspareunia among women planned for hysterectomy. Notably, studies of dyspareunia in POP frequently use the Pelvic Organ Prolapse/Incontinence Sexual Questionnaire [38] and the Female Sexual Function Index [39], which do not distinguish superficial and deep dyspareunia.

Conceptually, any POP at the top of the vagina, such as a rectocele and/or apical prolapse at the pouch of Douglas, could contribute to the symptom of deep dyspareunia, and it would be interesting to know whether there is a difference between the compartments in producing the symptom of deep dyspareunia.

Treatment options for POP include pelvic floor physiotherapy, pessaries, and surgery. Previous research has not examined the effect of pessaries and pelvic floor physiotherapy on the specific outcome of deep dyspareunia, however these treatments are associated with increased frequency and satisfaction in sexual intercourse, and less inference of prolapse symptoms with sex life [38, 40, 41]. Minimally invasive or open repair for POP, with or without mesh, has not consistently been shown to decrease dyspareunia [42-45] and de novo dyspareunia after transvaginal mesh surgery may occur in a proportion of cases (4.5-27\%) [46].

\section{$\underline{\text { Uterus-cervix }}$}

Tu and As-Sanie have proposed a clinical diagnosis of “chronic uterine pain”, defined as pain in the midline deep pelvis (not caused by a non-uterine diagnosis), for 3 months, > 10 days/month, 
and reproducible on uterine palpation on examination [47]. This clinical diagnosis is akin to the clinical diagnostic criteria for painful bladder syndrome and irritable bowel syndrome. Below are underlying diagnoses that could produce a tender uterus and chronic uterine pain. Although not evaluated in the literature, a possible strategy to reduce deep dyspareunia across these underlying diagnoses could be changes in position that avoid direct contact with the cervixuterus.

\section{Endometriosis}

The uterine (eutopic) endometrium in endometriosis demonstrates local inflammation and estrogen production, as well as local neurogenesis, similar to what is seen in the ectopic lesions of endometriosis [14]. This uterine neuro-inflammation could lead to a tender uterus and to deep dyspareunia from contact with the cervix-uterus. Another potential mechanism is a restriction of mobility of the uterus due to endometriosis-associated adhesions (e.g. associated with deep infiltrating endometriosis), such that cervical-uterine contact during intercourse results in physical "pulling” on these adhesions.

\section{Pelvic Inflammatory Disease}

Pelvic inflammatory disease (PID) can manifest as endometritis, but also lead to salpingitis, oophoritis, and pelvic peritonitis, caused by the ascent of pathogens from the lower to the upper reproductive tract. Acute PID can lead to deep dyspareunia [48, 49]. Of more interest is chronic PID, which is listed as a cause of deep dyspareunia in multiple prior publications [50, 51]. 
However, there is little research into chronic PID and whether it really plays a role in persistent sexual pain. One study looking at the incidence of dyspareunia among Taiwanese women determined that female pelvic organ infections (i.e., PID) were a common cause of dyspareunia [52]. A previous randomized control trial found a decrease in abdominal and pelvic pain after short wave diathermy as a treatment for chronic PID; however, this study was limited by a small sample size and this is not a common treatment for PID [53]. To our knowledge there is no research that has established a mechanism linking chronic PID with deep dyspareunia or studied the effects of standard antibiotic treatment of acute PID on reducing risk of future deep dyspareunia.

\section{Pelvic Congestion Syndrome}

Pelvic congestion syndrome is a controversial entity characterized by the presence of ovarian vein reflux and peri-uterine pelvic varices [54]. This syndrome may be related to vasodilation as a result of increased estrogen [54, 55]. In a cohort of women with chronic pelvic pain, $31 \%$ had pelvic congestion syndrome, determined from pelvic exam, surgery, ultrasound, and venography $[54,55]$. In the general population, the prevalence of ovarian varices was $9.9 \%$, with more than half of those patients having clinical symptoms of pelvic congestion syndrome [54, 56]. Previous research found that $60.5 \%$ of a cohort of women with pelvic congestion syndrome (diagnosed by physical exam and/or ultrasound) had the symptom of dyspareunia, and additional studies identified dyspareunia and post-coital pain as common symptoms of pelvic congestion syndrome $[54,57,58]$. In another study, women with pelvic congestion syndrome had more dyspareunia compared to women with other pelvic pathology and compared to controls [59]. 
Treatment of pelvic congestion can include hormonal suppression, interventional radiology approaches to occlude the ovarian vein, or surgery. Women with pelvic congestion syndrome undergoing transcatheter foam sclerotherapy for treatment of pelvic varices reported a significant improvement in dyspareunia score 1, 3, 6 and 12 months after the procedure [57]. Ovarian and pelvic vein embolization also significantly reduced dyspareunia [54,60]. While research is needed to differentiate between deep and superficial dyspareunia in these cases, it is more likely that pelvic congestion syndrome is related to uterine tenderness that leads to deep dyspareunia.

\section{Fibroids}

Estimates of the incidence of fibroids vary from $4.5 \%$ to $68.6 \%$ depending on study population and diagnostic methods; about a quarter of women with fibroids report deep dyspareunia [61, 62]. Women with uterine fibroids were shown to be 2.8 times as likely to report moderate or severe dyspareunia than women without fibroids [63]. Interestingly, there may be higher rates of dyspareunia among women with both a personal and family history of fibroids, compared to women without such a family history [64]. Dyspareunia has also been attributed to fibroids that fill the pelvis [65, 66], as well as cervical fibroids that result in bulk-related symptoms [51]. In contrast, a study by Moshesh et al. [62] showed that fibroid burden was not associated with degree of sexual pain.

Several studies have shown that deep dyspareunia was more associated with fundal fibroids than with fibroids in other locations, which might be explained by extreme anteversion or retroversion of the uterus bringing the fundus (and the fundal fibroid) up close to the vaginal apex where it can be contacted with deep penetration [51, 62, 63, 67]. In terms of treatment, myomectomy and 
laparoscopic hysterectomy improved mean pain scores on the Female Sexual Function Index [68, 69] and women receiving medical or complementary interventions reported improved dyspareunia scores in one prospective study of women with symptomatic fibroids [70].

\section{Uterine Position}

Uterine retroversion can be congenital or acquired and manifests as the uterine fundus oriented towards the spine and posterior pelvis (pouch of Douglas). Approximately 20\% of women have a retroverted uterus and it has been reported that up to two thirds experience sexual pain [71]. In a population-based study, Fauconnier et al. [71] found that women with uterine retroversion experience dyspareunia more frequently and with more severity than women with anteverted or

intermediary (axial) uteri, suggesting a uterine retroversion can be causally related to painful sex. The mechanism driving dyspareunia in uterine retroversion may be related to penile collision with the uterus in the pouch of Douglas, or stretching of the uterosacral ligaments to accommodate the anterior shift of the cervix [71, 72]. That being said, there are many women with retroverted uteri that report no deep dyspareunia, suggesting other factors that may interact with a retroverted uterus to produce a tender uterus (e.g. local neuroinflammation). Observational studies have found that surgical suspension of the uterus significantly decreases dyspareunia among women with no significant pelvic pathology [73-75]; however, these results should be interpreted with caution until the efficacy of uterine suspension is confirmed in a randomized control trial [76].

\section{Adenomyosis}


Adenomyosis occurs when the endometrial cells that line the uterus are found in the myometrial layer of the uterus. In a large prospective study, Naftalin et al. [77] found that adenomyosis was present in almost $21 \%$ of women attending a general gynecological clinic. Notably, in $80 \%$ of cases adenomyosis was shown to coexist with other pelvic pathologies identified in this review [78], and to our knowledge no studies have examined the relationship between adenomyosis alone and deep dyspareunia. The contribution of adenomyosis to deep dyspareunia when other pathologies are present is unclear; for example Gonzales et al. [79] found that women with endometriosis and adenomyosis experienced more deep dyspareunia than women with endometriosis alone. In contrast, Ferrero et al. [80] showed that intensity of deep dyspareunia was the same across women who had bowel endometriosis with or without adenomyosis and that surgical intervention for endometriosis significantly reduced deep dyspareunia in all study groups.

\section{TYPE II: CO-MORBID CONDITIONS}

Deep dyspareunia may also be related to co-morbid non-gynecologic conditions including urological, gastrointestinal, and psychological conditions.

\section{$\underline{\text { Urological }}$}

Interstitial cystitis/Painful bladder syndrome

Interstitial cystitis/painful bladder syndrome (IC/PBS) is pain, pressure, and/or discomfort perceived to be related to the urinary bladder, or worse with a full bladder, associated with 
irritative symptoms in the absence of infection or other pathology, and may be a source of dyspareunia [58, 81, 82]. The prevalence of dyspareunia ranges from $49 \%$ to $90 \%$ in women with IC/PBS [10, 83-85]. In a study of women who underwent surgery for chronic pelvic pain, dyspareunia was found to be a risk factor for the diagnosis of IC [86]. In a prospectively recruited study of 47 women with confirmed diagnosis of IC/PBS according to the National Institutes of Health, National Institutes of Diabetes and Digestive and Kidney Disease, 32\% of these women described their dyspareunia as unbearable and an additional $49 \%$ had some dyspareunia but still took part in sexual activity [87]. In a large cohort of women with and without IC/PBS, a greater proportion of women with IC/PBS reported dyspareunia compared to controls [88].

Presumably, dyspareunia in IC/PBS is related, at least in part, due contact with the bladder during intercourse (with another mechanism being the pelvic floor dysfunction seen in IC/PBS, as described below under musculoskeletal). Irritation of the bladder during sexual intercourse may also exacerbate the symptoms of IC/PBS [83, 89, 90]. In a cohort of women with endometriosis, our group has recently found an association between severity of deep dyspareunia and bladder/pelvic floor tenderness and a diagnosis of IC/PBS, controlling for endometriosis disease specific factors [91]. Tenderness of the bladder and pelvic floor, as well as the diagnosis of PBS, have been associated with deep dyspareunia in previous literature as well [92, 93]. It should also be emphasized that IC/PBS is associated with vulvodynia [94], and thus is also related to superficial dyspareunia.

A multidisciplinary treatment plan, including physiotherapy, bladder training, dietary modifications, as well as a combination of oral and intra-vesical instillation therapies, can be used to treat IC/PBS [89]. A previous study showed that treatment with 3 weeks of 3 times/week 
bladder instillations resulted in improvement of dyspareunia among 57\% of participants at their follow-up appointment [95]. However, prospective, randomized trials are needed. Changing sexual positions so as to avoid penile contact with the bladder may reduce some of the pain experienced during sexual intercourse in women with IC/PBS.

\section{Recurrent urinary tract infection}

Recurrent urinary tract infections (UTI) may also be associated with deep dyspareunia [66], again via penile contact with an inflamed bladder base. Salonia et al. [96] found that $44 \%$ of women with urinary incontinence and/or lower urinary tract symptoms suffered from dyspareunia or non-coital genital pain, and $61 \%$ of these also complained of recurrent bacterial cystitis. A population based study of women across the United States determined that presence of urinary tract symptoms was associated with a 7 fold increased likelihood of having sexual pain [97]. In both these studies, there is probably a mix of patients with IC/PBS and true recurrent UTIs. Women with recurrent UTI can report pain that is either superficial or deeper [96], which may be related to local inflammation or negative impact on lubrication, and treatment can improve sexual pain [96]. More research is needed in terms of the relationship between recurrent UTIs and deep versus superficial dyspareunia.

\section{Gastrointestinal}

Irritable Bowel Syndrome 
Irritable bowel syndrome (IBS) is characterized by gas, bloating, cramping, diarrhea and/or constipation. A meta-analysis of IBS in the community found that $14 \%$ of women meet the criteria for this condition [98] and 16.4\% of women with IBS report dyspareunia [99].

Interestingly, the predominant constipation subtype of IBS is 2.38 times as common in women as men, and pain with intercourse is more common among women who have three or fewer bowel movements per week [100]. Pain with intercourse among women with IBS may result from collision of the penis with the constipated bowel that fills the pouch of Douglas, however the independence of the association between dyspareunia and IBS may require further scrutiny [91]. For example, after controlling for IC/PBS, one study did not observe an association between IBS and tender pelvic sites associated with deep dyspareunia [93].

\section{Inflammatory Bowel Disease}

Inflammatory bowel disease (IBD), including ulcerative colitis and Crohn's disease, varies significantly by geographic location and is as high as 23 cases per 100,000 person-years [101]. Between $18 \%$ and $40 \%$ of this population experiences painful penetration or intercourse [102], perhaps as a result of rectal inflammation and increased sensitivity in the adjacent pouch of Douglas, or in rare cases as a result of a fistula arising from the bowel that erodes into the vagina [103]. Dyspareunia in the IBD population is also related to IBS type symptoms, higher somatization scores, and perianal disease, but not with disease phenotype or other demographic factors [102, 104]. Increased dyspareunia may occur following surgical intervention [105], possibly as a result of altered anatomy or impacts on nervous supply that can reduce lubrication or vaginal proprioception [106]. It should be emphasized that IBD can also be associated with 
superficial dyspareunia, such as via vulvar Crohn’s lesions [107], and thus more work differentiating deep and superficial dyspareunia in this population is needed.

\section{$\underline{\text { Psychological diagnoses }}$}

\section{Depression and Anxiety}

The majority of research on the relationship between psychological diagnoses and sexual pain is focused on superficial dyspareunia; however, evidence suggests that at least in the case of concurrent dyspareunia (patients with both superficial and deep dyspareunia), depression remains an important consideration [108].

There is a known relationship between sexual pain and depression/anxiety, focused primarily on superficial dyspareunia due to PVD [109-113]. Women with dyspareunia or provoked vestibulodynia (PVD) have been shown to have higher depression scores than controls, and depression is also associated with tenderness of the bladder and pelvic floor as well as a four times increased risk of vulvodynia [93, 109, 111]. Similarly, studies have shown that anxiety disorders are risk factors for sexual pain and that diagnosis of an anxiety disorder is ten times more common in women with PVD $[109,114,115]$. In one case-control study, the prevalence of depression and anxiety was significantly greater in women who reported dyspareunia symptoms compared to women without dyspareunia [116].

The direction of the relationship between psychopathology and sexual pain is likely bidirectional; depression and anxiety are considered both risk factors and consequences of PVD [115]. To our knowledge, no research has examined the impact of specific treatment for 
depression or anxiety on deep dyspareunia, however caution is needed with drugs such as selective serotonin reuptake inhibitors given potential impact on sexual functioning. In contrast, psychotherapeutic approaches may work to reduce sexual pain: cognitive behavioural therapy and mindfulness are used in the treatment of depression and anxiety and are also effective in the treatment of PVD [115]. Further research is also needed in the potential role of psychological factors and their treatment in deep dyspareunia. In a recent published observational 1 year cohort for deep dyspareunia, a multidisciplinary approach including psychological therapies was associated with decreased deep dyspareunia at 1 year [117].

\section{$\underline{\text { Musculoskeletal conditions }}$}

\section{Myofascial pain syndrome}

Myofascial pain syndrome arises from myofascial trigger points - exquisitely tender spots in taut bands of muscle. Myofascial pain and trigger points in the muscles of the pelvic floor is associated with dyspareunia $[118,119]$; in one study dyspareunia was the presenting symptom among $47 \%$ of women receiving medical treatment of pelvic floor trigger points [120], and in another 86\% endorsed deep dyspareunia [121]. Whereas superficial pain has been associated with dysfunction of the outer third of the vaginal musculature, deep dyspareunia has been attributed to trigger points on the posterior levator ani or obturator internus muscles [122], perhaps because these muscles are likely to be impacted with deeper penetration. Trigger points in deep pelvic floor muscles can refer pain sensation to the back, hips, and legs; this suggests that although deep dyspareunia occurs with deep penetration of the vagina, perception of the pain may not be limited to the vagina or even the pelvis [122]. 
Treatment for myofascial pelvic pain includes pelvic floor physiotherapy or injection of local anesthetics and/or Botox , both of which can significantly reduce dyspareunia [120,121]. On the other hand, in a placebo controlled randomized trial, reduction in sexual pain did not differ between women treated with Botox versus saline injection [123] and a pilot randomized trial of physiotherapy versus injection with local anaesthetic and steroid showed that physiotherapy may be more efficacious in addressing deep dyspareunia [121].

A full discussion of vaginismus is outside the context of this review. However, a vaginistic response is likely to preclude penetration, and thus may be more a consideration for superficial dyspareunia, rather than deep dyspareunia.

\section{TYPE III: GPPPD AND CENTRAL NERVOUS SYSTEM SENSITIZATION}

In the DSM-V, genito-pelvic pain penetration disorder (GPPPD) is inclusive of both deep and superficial dyspareunia, and includes cases of dyspareunia not due to another medical condition (such as gynecological or non-gynecological diagnoses). We have previously proposed that in women with endometriosis, deep dyspareunia due to central nervous system sensitization may be related to GPPPD [5].

Central sensitization refers to the enhancement in the function of the neurons that results in an increased sensation of pain (hyperalgesia) or a sensation of pain from a non-painful stimulus (allodynia) [124]. Cross sensitization occurs when a pathologically painful organ/structure can lead to a non-painful organ/structure becoming painful [125-127]. This happens when nonpainful afferent signals "jump the tract” and are processed through afferent pain pathways causing non-painful stimuli to be perceived as pain. In the literature, sensitization of the nervous 
system is assessed through quantitative sensory testing (e.g., a lower pain-pressure threshold would indicate greater sensitization), brain magnetic resonance imaging (MRI), or the use of standardized questions for symptoms commonly seen in sensitized patients [124, 128]. Clinically, patients with central sensitization tend to have multiple pain diagnoses (e.g. fibromyalgia) and multiple body regions of pain, hyperalgesia, and allodynia.

Several studies have linked central sensitization and dyspareunia. In a study comparing women with dyspareunia to controls, women with dyspareunia had significantly lower pain pressure thresholds and a higher number of tender points, compared to controls [129]. Another study showed that among women with pelvic pain, intercourse pain was significantly associated with lower pressure thresholds at pelvic and extra-pelvic sites [130]. A study by Zhang et al., comparing women with superficial dyspareunia and healthy controls suggested that women with a longer history of superficial dyspareunia may be centrally sensitized [131]. In a study comparing women with superficial dyspareunia to healthy controls, a greater level of activation in the insula, dorsal mid-cingulate, posterior cingulate and thalamus was detected on fMRI during thumb stimulation in the women with pain [132]. In addition, As-Sanie et al. found that women with pelvic pain, with and without endometriosis, had decreased grey matter volume in left thalamus (a region in the brain involved in pain perception) [133].

Central sensitization may require a multidisciplinary approach. Pain adjuvants such as tricyclic antidepressants and trigger point injections have been studied in preliminary research, and psychological treatments like cognitive behavioural therapy and mindfulness based therapy have been suggested as another avenue for management $[67,124,134]$. Physiotherapy is also likely to be important; for example, women with superficial dyspareunia who underwent treatment with vaginal electromyographic feedback had a reduction of pain and could return to engaging in 
intercourse [135]. In the recent published observational 1 year cohort for deep dyspareunia showing possible benefit for a multidisciplinary approach, pelvic physiotherapy was part of the multimodal treatment [117].

\section{TYPE IV: MIXED}

Type IV cases are those with multiple contributors to deep dyspareunia: whether gynecological, another comorbid condition, or central sensitization. An example would be the patient with known severe endometriosis (e.g. through ultrasound diagnosis of deep infiltrating endometriosis), who also has PBS/IC and evidence of central sensitization. It is not clear as to the ideal management of such patients. Surgically removing the gynecological pain stimulus could potentially reduce signaling to the central nervous system and reduce sensitization; on the other hand, surgery in a sensitized patient may worsen pain and result in a prolonged postoperative recovery. Alternatively, psychological or physiotherapy treatments could be utilized pre-operatively, and perhaps improve response to surgery, or even alleviate the deep dyspareunia and avoid the need for surgery altogether. This population of mixed etiology is deserving of more investigation.

\section{SOCIOCULTURAL AND GENETIC FACTORS}

Ethnicity appears to affect pain perception and reporting, which may be due to sociocultural factors or genetics. For example, studies using quantitative sensory testing have suggested ethnic differences in response to experimental pain stimuli [136-138]. The differences between 
ethnicities may be attributed to social factors, such as socioeconomic status that may delay access to health care and thus contribute to increased severity of pain [139]. Another potential reason for discrepancies in pain between ethnicities may be genetics. Some women who have signs of central sensitization may have a genetic predisposition to autonomous pain amplification [140]. It has been suggested that people with chronic pain conditions have an impairment of endogenous inhibitory controls, which may be affected in part by genetic factors [125, 141]. It is possible these factors may vary by ethnicity, but at this point, any ethnic differences in the pathophysiology of deep dyspareunia severity are theoretical only.

Endometriosis is a common cause of deep dyspareunia and the genetics of endometriosis have been studied more intensively [142]. In the endometriosis literature, large-scale GWAS studies have identified approximately 12 loci associated with endometriosis risk, with these associations being stronger with more severe stage endometriosis. Recent work by our group has also identified somatic KRAS codon 12 mutations in the endometriosis epithelial cells in 26\% of women with deep infiltrating endometriosis [143]. More invasive endometriosis of the pouch of Douglas is associated with more deep dyspareunia; thus, these genetic findings may play a role in the etiology and severity of deep dyspareunia.

There has not been much research on the genetics of dyspareunia specifically; however, recent studies looked at vulvar vestibulitis syndrome (PVD and superficial dyspareunia) have been reviewed [144]. A previous study by Heddini et al., determined that women carrying the 1438Gand 102C-alleles of the serotonin receptor gene (5HT-2A) had an elevated probability of having provoked vestibulodynia (which is a common type of dyspareunia) compared to healthy controls [145]. A study by Goldstein et al., found that women with vestibulodynia who were taking combined hormonal contraceptives were more likely to have longer cytosine-adenine- 
guanine repeats in the androgen receptor, compared to women who did not develop vestibulodynia but took the same combined hormonal contraceptives [146]. Presence of allele 2 in the interleukin-1b gene was found to be more common in vulvar vestibulitis syndrome compared to healthy controls [147]. Finding that certain gene polymorphisms are more common in women with vulvodynia may allude to the presence of risk-associated polymorphisms in some women with deep dyspareunia; however, genetic research looking specifically at deep dyspareunia is required.

\section{SEXUAL RESPONSE}

The Basson Sexual Response Cycle (Figure 1) demonstrates that emotional intimacy, sexual stimuli, sexual arousal, and physical and emotional satisfaction affect female sexual response in a non-linear way [148]. Disruption at any point in the cycle can contribute to sexual pain. For example, a woman who has a persistent inability to obtain or sustain arousal may experience sexual discomfort as a result of reduced physiological response. Pain also begets pain (Figure 2); this has been borne out in classical conditioning experiments showing that pairing sexual stimuli with pain negatively affects sexual response [149]. As a consequence, dyspareunia is associated with several other aspects of sexual functioning such as vaginal dryness, difficulty reaching climax, and a lack of pleasurable sex [150]. It is important to note that research in this field either focuses on superficial dyspareunia or dyspareunia in general, and there is a need to empirically validate this model in deep dyspareunia [151] [152] (Figures 1-2). 
The role of the sexual response cycle may be particularly important in women with pain catastrophizing cognitions. In particular, women who magnify, ruminate, or feel helpless about their deep dyspareunia may have a more amplified negative feedback response to their pain. Women with chronic pelvic pain have been shown to exhibit significant pain-related psychological involvement such as catastrophizing, fear and hypervigilance to pain during intercourse [130]. Another study demonstrated positive correlations between pain catastrophizing scores and dyspareunia [153].

\section{RESEARCH PRIORITIES}

There appear to be several promising avenues for exploration of the pathophysiology and treatment of deep dyspareunia. We consider the following to be important considerations for researchers investigating deep dyspareunia:

\section{1) Measurement of Deep Dyspareunia}

Only a minority of studies included in this review distinguished between deep dyspareunia and superficial dyspareunia. Given that there are often different causes, and therefore treatments, for these types of sexual pain, we recommend a focus on standardizing and validating a patientreported measure for deep dyspareunia. This measure should consider recall period as previous research has found that asking women about dyspareunia in a recall period of more than one month resulted in a lower prevalence of sexual pain $[51,154]$. In addition, an objective measure of deep dyspareunia requires development, analogous to the vulvalgesiometer or tampon test in PVD $[155,156]$. 


\section{2) Intercourse Avoidance}

Across types of deep dyspareunia, researchers commented that a limitation of their research was the under-representation of intercourse-avoidant individuals (i.e., inclusion criteria were sexual activity, however patients with severe pain were often not currently sexually active and therefore excluded). Under-representation introduces bias potentially leading to the misrepresentation of treatment efficacy. We propose that women who abstain from sex due to pain should be included as a unique group in research.

\section{3) Comorbidities}

Many of the conditions described in this review frequently co-occur, thus it is difficult to establish causal relationships between any condition and deep dyspareunia. When studying the relationship between deep dyspareunia and particular condition, we recommend that researchers assess for other comorbidities, in order to control for confounding.

\section{4) Sociodemographics}

Difference in deep dyspareunia between ethnicities was not consistently reported in any of the reviewed studies despite research showing differences in pain perception and reporting between ethnicities [136-138]. We suggest stratifying study populations by ethnicity and acculturation to

tease out differences between genetic, cultural, and economic factors. We also recommend study of LGBTQ individuals; in one study, the association between deep dyspareunia and sexual quality-of-life varied by sexual orientation [157].

\section{5) Clinical Trials}


Many studies we considered treated sexual pain as a secondary outcome, in particular randomized trials in endometriosis. We advise designing appropriately powered randomized control trials for sexual outcomes, in order to detect significant differences in deep dyspareunia in well-defined study populations, such as after treatment for endometriosis or IC/PBS.

\section{6) Partner Variables}

Of the reviewed papers, several mentioned partner characteristics as an uncontrolled factor that may affect dyspareunia. Male factors including phallus size as well as erectile and ejaculatory function may exacerbate deep dyspareunia. Moreover, relationship factors including level of trust and communication are likely to contribute to the self-management of sexual pain. Future research should examine the relationship between partner variables and deep dyspareunia.

\section{7) Psychological Factors}

A number of the reviewed articles identified psychological variables and sexual abuse as factors associated with sexual pain. The mechanisms underlying these relationships in deep dyspareunia, as well as the directionality of causation, both remain unclear. Therefore, we suggest studies examining the causality of these factors. For example, in a longitudinal prospective cohort, depression severity at baseline predicted worse deep dyspareunia at 1 year [117]. A clinical trial of depression treatment, with deep dyspareunia as the primary outcome, would be of particular interest.

\section{8) Personalized treatment}

The proposed framework in this review, whereby patients can be stratified by type of deep dyspareunia, requires further study for empirical validation. In addition to clinical trials of 
treatments for conditions such as endometriosis and IC/PBS, there is a need for investigation of adjunct sexual health treatments specific to deep dyspareunia. This includes psychological and physiotherapy interventions, as well as spacers that limit depth of penetration and other selfmanagement techniques (e.g., optimal positions for intercourse). Empirical validation of the sexual response cycle for deep dyspareunia is also needed, and sex therapy targeted to optimizing this cycle may be another treatment option in women with deep dyspareunia.

\section{Conclusions}

In this review, we described the pathophysiology of deep dyspareunia, as summarized in Figure 3 , as well as potential treatments. Additionally, we proposed eight research priorities that highlighted the gaps in the existing literature about deep dyspareunia. In order for rigorous investigation of deep dyspareunia to proceed, researchers should develop and adopt valid measures of deep dyspareunia (patient-reported or objective). In future studies, special consideration should be given to the characteristics of study population including previously under-explored variables such as sociodemographics. Finally, clinical trials with adequate power for sexual pain are needed in deep dyspareunia. 


\section{$\underline{\text { References }}$}

[1] Hayes RD, Bennett CM, Dennerstein L, Taffe JR, Fairley CK. Are aspects of study design associated with the reported prevalence of female sexual difficulties? Fertil Steril 2008;90:497505.

[2] Gandhi J, Khan SA. A vicious cycle of causes and consequences of dyspareunia: rethinking the approach to management of genitourinary syndrome of menopause. Am J Obstet Gynecol 2017;217:625.

[3] Donaldson RL, Meana M. Early dyspareunia experience in young women: Confusion, consequences, and help esking barriers. J Sex Med 2011;8:814-823.

[4] Vercellini P, Meana M, Hummelshoj L, Somigliana E, Viganò P, Fedele L. Priorities for endometriosis research: a proposed focus on deep dyspareunia. Reprod Sci 2011;18:114-118.

[5] Yong PJ. Deep Dyspareunia in Endometriosis: A Proposed Framework Based on Pain Mechanisms and Genito-Pelvic Pain Penetration Disorder. Sex Med Rev 2017. doi:

10.1016/j.sxmr.2017.06.005. PubMed PMID: 28778699.

[6] Smith RPMD. Dyspareunia : Deep Thrust. Third ed2018. p. 73-75.

[7] Hummelshoj L, Graaff AD, Dunselman G, Vercellini P. Let's talk about sex and endometriosis. J Fam Plann Reprod Health Care 2014;40:8-10. doi: 10.1136/jfprhc-2012100530.

[8] Fauconnier A, Staraci S, Huchon C, Roman H, Panel P, Descamps P. Comparison of patientand physician-based descriptions of symptoms of endometriosis: a qualitative study. Hum Reprod 2013;28:2686-2694. doi: 10.1093/humrep/det310. 
[9] Capaccione KM, Levin M, Tchabo N, Darcey J, Amorosa J. Massive endometrioma presenting with dyspnea and abdominal symptoms. Radiol Case Rep 2017;12:741-745. doi: 10.1016/j.radcr.2017.06.009.

[10] Ferrero S, Esposito F, Abbamonte LH, Anserini P, Remorgida V, Ragni N. Quality of sex life in women with endometriosis and deep dyspareunia. Fertil Steril 2005;83:573-579. doi: 10.1016/j.fertnstert.2004.07.973. PubMed PMID: 15749483.

[11] Kho RM, Abrao MS. Ovarian remnant syndrome: etiology, diagnosis, treatment and impact of endometriosis. Curr Opin Obstet Gynecol 2012;24:210-214.

[12] Williams C, Hoang L, Yosef A, Alotaibi F, Allaire C, Brotto L, Fraser IS, Bedaiwy MA, Ng TL, Lee AF, Yong PJ. Nerve Bundles and Deep Dyspareunia in Endometriosis. Reprod Sci 2016;23:892-901. doi: 10.1177/1933719115623644. PubMed PMID: 26711313.

[13] Peng B, Zhan H, Alotaibi F, Alkusayer GM, Bedaiwy MA, Yong PJ. Nerve Growth Factor Is Associated With Sexual Pain in Women With Endometriosis. Reprod Sci 2017:1933719117716778.

[14] Bulun SE. Endometriosis. N Engl J Med 2009;360:268-279.

[15] Gueuvoghlanian-Silva BY, Bellelis P, Barbeiro DF, Hernandes C, Podgaec S. Treg and NK cells related cytokines are associated with deep rectosigmoid endometriosis and clinical symptoms related to the disease. J Reprod Immunol 2018;126:32-38. doi:

10.1016/j.jri.2018.02.003.

[16] Taylor HS, Giudice LC, Lessey BA, Abrao MS, Kotarski J, Archer DF, Diamond MP, Surrey E, Johnson NP, Watts NB. Treatment of endometriosis-associated pain with elagolix, an oral GnRH antagonist. N Eng J Med 2017;377:28-40. 
[17] Kingsberg SA, Wysocki S, Magnus L, Krychman ML. Vulvar and vaginal atrophy in postmenopausal women: findings from the REVIVE (REal Women's VIews of Treatment Options for Menopausal Vaginal ChangEs) survey. J Sex Med 2013;10:1790-1799. doi: 10.1111/jsm.12190.

[18] Robson M, Hensley M, Barakat R, Brown C, Chi D, Poynor E, Offit K. Quality of life in women at risk for ovarian cancer who have undergone risk-reducing oophorectomy. Gynecol Oncol 2003;89:281-287.

[19] Colombo N, Van Gorp T, Parma G, Amant F, Gatta G, Sessa C, Vergote I. Ovarian cancer. Crit Rev Oncol Hematol 2006;60:159-179.

[20] Gandhi J, Chen A, Dagur G, Suh Y, Smith N, Cali B, Khan SA. Genitourinary syndrome of menopause: an overview of clinical manifestations, pathophysiology, etiology, evaluation, and management. Am J Obstet Gynecol 2016;215:704-711. doi: 10.1016/j.ajog.2016.07.045.

[21] Matthes A, Zucca Matthes G. Current commentaries about deep dyspareunia and the genitourinary syndrome of menopause. Clin Obstet Gynecol Reprod Med 2016;2. doi: 10.15761/COGRM.1000168.

[22] Labrie F, Archer D, Bouchard C, Fortier M, Cusan L, Gomez J-L, Girard G, Baron M, Ayotte N, Moreau M. Effect of intravaginal dehydroepiandrosterone (Prasterone) on libido and sexual dysfunction in postmenopausal women. Menopause 2009;16:923-931.

[23] Bachmann GA, Komi JO, Group OS. Ospemifene effectively treats vulvovaginal atrophy in postmenopausal women: results from a pivotal phase 3 study. Menopause 2010;17:480-486.

[24] Morris L, Do V, Chard J, Brand AH. Radiation-induced vaginal stenosis: current perspectives. Int J Womens Health 2017;9:273-279. doi: 10.2147/IJWH.S106796. 
[25] Francis WJ, Jeffcoate TN. Dyspareunia following vaginal operations. J Obstet Gynaecol Br Commonw 1961;68:1-10.

[26] Bergmark K, Åvall-Lundqvist E, Dickman PW, Henningsohn L, Steineck G. Vaginal changes and sexuality in women with a history of cervical cancer. N Eng J Med 1999;340:13831389.

[27] Fanfani F, Landoni F, Gagliardi ML, Fagotti A, Preti E, Moruzzi MC, Monterossi G, Scambia G. Sexual and reproductive outcomes in early stage cervical cancer patients after excisional cone as a fertility-sparing surgery: an Italian experience. J Reprod Infertil 2014;15:29. [28] Siedhoff MT, Carey ET, Findley AD, Hobbs KA, Moulder JK, Steege JF. Posthysterectomy dyspareunia. J Minim Invasive Gynecol 2014;21:567-575.

[29] Abdelmonem AM. Vaginal length and incidence of dyspareunia after total abdominal versus vaginal hysterectomy. Eur J Obstet Gynecol Reprod Biol 2010;151:190-192.

[30] Feiner B, O’Rourke P, Maher C. A prospective comparison of two commercial mesh kits in the management of anterior vaginal prolapse. Int Urogynecol J 2012;23:279-283.

[31] De Tayrac R, Cornille A, Eglin G, Guilbaud O, Mansoor A, Alonso S, Fernandez H. Comparison between trans-obturator trans-vaginal mesh and traditional anterior colporrhaphy in the treatment of anterior vaginal wall prolapse: results of a French RCT. Int Urogynecol J 2013;24:1651-1661.

[32] Antosh DD, Gutman RE, Park AJ, Sokol AI, Peterson JL, Kingsberg SA, Iglesia CB. Vaginal dilators for prevention of dyspareunia after prolapse surgery: a randomized controlled trial. Obstet Gynecol 2013;121:1273-1280.

[33] Vollebregt A, Fischer K, Gietelink D, Van der Vaart C. Primary surgical repair of anterior vaginal prolapse: a randomised trial comparing anatomical and functional outcome between 
anterior colporrhaphy and trocar

1527.

[34] Stinesen Kollberg K, Waldenström A-C, Bergmark K, Dunberger G, Rossander A, Wilderäng U, Åvall-Lundqvist E, Steineck G. Reduced vaginal elasticity, reduced lubrication, and deep and superficial dyspareunia in irradiated gynecological cancer survivors. Acta oncologica 2015;54:772-779.

[35] Nygaard I, Barber MD, Burgio KL, Kenton K, Meikle S, Schaffer J, Spino C, Whitehead WE, Wu J, Brody DJ, Pelvic Floor Disorders N. Prevalence of symptomatic pelvic floor disorders in US women. JAMA 2008;300:1311-1316. doi: 10.1001/jama.300.11.1311. [36] Burrows LJ, Meyn LA, Walters MD, Weber AM. Pelvic symptoms in women with pelvic organ prolapse. Obstet Gynecol 2004;104:982-988. doi: 10.1097/01.AOG.0000142708.61298.be. [37] Handa VL, Harvey L, Cundiff GW, Siddique SA, Kjerulff KH. Sexual function among women with urinary incontinence and pelvic organ prolapse. Am J Obstet Gynecol 2004;191:751-756. doi: 10.1016/j.ajog.2003.11.017.

[38] Abdool Z, Thakar R, Sultan AH, Oliver RS. Prospective evaluation of outcome of vaginal pessaries versus surgery in women with symptomatic pelvic organ prolapse. Int Urogynecol J 2011;22:273-278. doi: 10.1007/s00192-010-1340-9.

[39] Rosen CB. The Female Sexual Function Index (FSFI): a multidimensional self-report instrument for the assessment of female sexual function. J Sex Marital Ther 2000;26:191-208. [40] Fernando RJ, Thakar R, Sultan AH, Shah SM, Jones PW. Effect of vaginal pessaries on symptoms associated with pelvic organ prolapse. Obstet Gynecol 2006;108:93-99. doi: 10.1097/01.AOG.0000222903.38684.cc. 
[41] Kuhn A, Bapst D, Stadlmayr W, Vits K, Mueller MD. Sexual and organ function in patients with symptomatic prolapse: are pessaries helpful? Fertil Steril 2009;91:1914-1918. doi: 10.1016/j.fertnstert.2008.02.142.

[42] Sentilhes L, Berthier A, Sergent F, Verspyck E, Descamps P, Marpeau L. Sexual function in women before and after transvaginal mesh repair for pelvic organ prolapse. Int Urogynecol J 2008;19:763-772. doi: 10.1007/s00192-007-0521-7.

[43] Farthmann J, Mengel M, Henne B, Grebe M, Watermann D, Kaufhold J, Stehle M, Fuenfgeld C. Improvement of pelvic floor-related quality of life and sexual function after vaginal mesh implantation for cystocele: primary endpoint of a prospective multicentre trial. Arch Gynecol Obstet 2016;294:115-121. doi: 10.1007/s00404-016-4014-0.

[44] Gupta P, Payne J, Killinger KA, Ehlert M, Bartley J, Gilleran J, Boura JA, Sirls LT. Analysis of changes in sexual function in women undergoing pelvic organ prolapse repair with abdominal or vaginal approaches. Int Urogynecol J 2016;27:1919-1924. doi: 10.1007/s00192016-3066-9.

[45] Hagen S, Stark D, Glazener C, Dickson S, Barry S, Elders A, Frawley H, Galea MP, Logan J, McDonald A, McPherson G, Moore KH, Norrie J, Walker A, Wilson D. Individualised pelvic floor muscle training in women with pelvic organ prolapse (POPPY): a multicentre randomised controlled trial. Lancet 2014;383:796-806. doi: 10.1016/S0140-6736(13)61977-7.

[46] Hugele F, Panel L, Farache C, Kashef A, Cornille A, Courtieu C. Two years follow up of 270 patients treated by transvaginal mesh for anterior and/or apical prolapse. Eur J Obstet Gynecol Reprod Biol 2017;208:16-22. doi: 10.1016/j.ejogrb.2016.10.015.

[47] Tu F, As -Sanie S. A modest propo 2017;124:182-184. 
[48] Ross J, Guaschino S, Cusini M, Jensen J. 2017 European guideline for the management of pelvic inflammatory disease. Int J STD AIDS 2018;29:108-114. doi:

$10.1177 / 0956462417744099$.

[49] Ross JDC. Pelvic inflammatory disease. Medicine 2014;42:333-337. doi:

10.1016/j.mpmed.2014.03.010.

[50] Canavan TP, Heckman CD. Dyspareunia in women: Breaking the silence is the first step toward treatment. Postgrad Med J 2000;108:149-166.

[51] Goldstein AT, Pukall C, Goldstein I. Female sexual pain disorders: Evaluation and management: John Wiley \& Sons; 2011.

[52] Liu HL, Lee HM, Chung YC. Dyspareunia and Its Comorbidities among T aiwanese Women: Analysis of the 2004-2010 Nationwide Health Insurance Database. J Sex Med 2015;12:1012-1018.

[53] Lamina S, Hanif S, Gagarawa YS. Short wave diathermy in the symptomatic management of chronic pelvic inflammatory disease pain: A randomized controlled trial. Physiother Res Int 2011;16:50-56.

[54] Durham JD, Machan L, editors. Pelvic congestion syndrome. Seminars in interventional radiology; 2013: Thieme Medical Publishers.

[55] Soysal ME, Soysal S, Vicdan K, Ozer S. A randomized controlled trial of goserelin and medroxyprogesterone acetate in the treatment of pelvic congestion. Hum Reprod 2001;16:931939.

[56] Belenky A, Bartal G, Atar E, Cohen M, Bachar GN. Ovarian varices in healthy female kidney donors: incidence, morbidity, and clinical outcome. Am J Roentgenol 2002;179:625-627. 
[57] Gandini R, Chiocchi M, Konda D, Pampana E, Fabiano S, Simonetti G. Transcatheter foam sclerotherapy of symptomatic female varicocele with sodium-tetradecyl-sulfate foam. J Vasc Interv Radiol 2008;31:778-784.

[58] Vercellini P, Daguati R, Abbiati A. Chronic pelvic pain. Non-invasive management of gynecologic disorders 2008:33-51.

[59] Beard R, Reginald P, Wadsworth J. Clinical features of women with chronic lower abdominal pain and pelvic congestion. BJOG 1988;95:153-161.

[60] Kim HS, Malhotra AD, Rowe PC, Lee JM, Venbrux AC. Embolotherapy for pelvic congestion syndrome: long-term results. J Vasc Interv Radiol 2006;17:289-297.

[61] Stewart EA, Cookson CL, Gandolfo RA, Schulze -Rath R. Epidemiolog. fibroids: a systematic review. BJOG;124:1501-1512. doi: 10.1111/1471-0528.14640.

[62] Moshesh M, Olshan AF, Saldana T, Baird D. Examining the Relationship Between Uterine Fibroids and Dyspareunia Among Premenopausal Women in the United States. J Sex Med 2014;11:800-808. doi: 10.1111/jsm.12425.

[63] Lippman SA, Warner M, Samuels S, Olive D, Vercellini P, Eskenazi B. Uterine fibroids and gynecologic pain symptoms in a population-based study. Fertil Steril 2003;80:1488-1494. [64] Okolo S, Gentry C, Perrett C, Maclean A. Familial prevalence of uterine fibroids is associated with distinct clinical and molecular features. Hum Reprod 2005;20:2321-2324. [65] Gupta S, Jose J, Manyonda I. Clinical presentation of fibroids. Best Pract Res Clin Obstet Gynecol 2008;22:615-626.

[66] Berman JR, Bassuk J. Physiology and pathophysiology of female sexual function and dysfunction. World J Urol 2002;20:111-118. 
[67] Bedaiwy MA, Alfaraj S, Yong P, Casper R. New developments in the medical treatment of endometriosis. Fertil Steril 2017;107:555-565.

[68] Till SR, Hobbs KA, Moulder JK, Martin CE, Siedhoff MT. Change in Sexual Function at One Year Among Women Undergoing Hysterectomy for Pain-Related Verses Non-Pain Indications. J Minim Invasive Gynecol 2015;22:S16. doi: 10.1016/j.jmig.2015.08.051.

[69] Ertunc D, Uzun R, Tok EC, Doruk A, Dilek S. The effect of myoma uteri and myomectomy on sexual function. J Sex Med 2009;6:1032-1038.

[70] Jacoby VL, Jacoby A, Learman LA, Schembri M, Gregorich SE, Jackson R, Kuppermann M. Use of medical, surgical and complementary treatments among women with fibroids. Eur J Obstet Gynecol Reprod Biol 2014;182:220-225. doi: 10.1016/j.ejogrb.2014.09.004.

[71] Fauconnier A, Dubuisson J-B, Foulot H, Deyrolles C, Sarrot F, Laveyssière M-N, JanséMarec J, Bréart G. Mobile uterine retroversion is associated with dyspareunia and dysmenorrhea in an unselected population of women. Eur J Obstet Gynecol Reprod Biol 2006;127:252-256. doi: 10.1016/j.ejogrb.2005.11.026.

[72] Carter JE. Surgical Treatment for Chronic Pelvic Pain. JSLS 1998;2:129-139.

[73] Yen C-F, Wang C-J, Lin S-L, Lee C-L, Soong Y-K. Combined laparoscopic uterosacral and round ligament procedures for treatment of symptomatic uterine retroversion and mild uterine decensus. J Am Assoc Gynecol Laparosc 2002;9:359-366.

[74] Carter JE. Carter-Thomason uterine suspension and positioning by ligament investment, fixation and truncation. J Reprod Med 1999;44:417-422.

[75] Gargiulo T, Leo L, Gomel V. Laparoscopic uterine suspension using three-stitch technique. J Am Assoc Gynecol Laparosc 2000;7:233-236. doi: 10.1016/S1074-3804(00)80046-8. 
[76] Howard F. Is Uterine Retroversion and Retroflexion a Disease That Requires Surgical Correction? J Minim Invasive Gynecol 2010;17:671-672. doi: 10.1016/j.jmig.2010.08.693. [77] Naftalin J, Hoo W, Pateman K, Mavrelos D, Holland T, Jurkovic D. How common is adenomyosis? A prospective study of prevalence using transvaginal ultrasound in a gynaecology clinic. Hum Reprod 2012;27:3432-3439. doi: 10.1093/humrep/des332.

[78] Peric H, Fraser IS. The symptomatology of adenomyosis. Best Pract Res Clin Obstet Gynecol 2006;20:547-555. doi: 10.1016/j.bpobgyn.2006.01.006.

[79] Gonzales M, Matos LAd, Gonçalves MOdC, Blasbalg R, Junior JAD, Podgaec S, Baracat EC, Abrão MS. Patients with adenomyosis are more likely to have deep endometriosis. Gynecol Surg 2012;9:259-264. doi: 10.1007/s10397-012-0746-4.

[80] Ferrero S, Camerini G, Menada MV, Biscaldi E, Ragni N, Remorgida V. Uterine adenomyosis in persistence of dysmenorrhea after surgical excision of pelvic endometriosis and colorectal resection. J Reprod Med 2009;54:366-372.

[81] Hanno PM, Burks DA, Clemens JQ, Dmochowski RR, Erickson D, FitzGerald MP, Forrest JB, Gordon B, Gray M, Mayer RD. AUA guideline for the diagnosis and treatment of interstitial cystitis/bladder pain syndrome. J Urol 2011;185:2162-2170.

[82] Heim LJ. Evaluation and differential diagnosis of dyspareunia. Am Fam Physician 2001;63:1535-1556.

[83] Kellogg-Spadt S, Albaugh JA. Intimacy and bladder pain: helping women reclaim sexuality. Urol Nurs 2002;22:355-356.

[84] Parsons CL, Dell J, Stanford EJ, Bullen M, Kahn BS, Waxell T, Koziol JA. Increased prevalence of interstitial cystitis: previously unrecognized urologic and gynecologic cases 
identified using a new symptom questionnaire and intravesical potassium sensitivity. Urology 2002;60:573-578.

[85] Bogart LM, Suttorp MJ, Elliott MN, Clemens JQ, Berry SH. Prevalence and correlates of sexual dysfunction among women with bladder pain syndrome/interstitial cystitis. Urology 2011;77:576-580.

[86] Clemons JL, Arya LA, Myers DL. Diagnosing interstitial cystitis in women with chronic pelvic pain. Obstet Gynecol 2002;100:337-341.

[87] Gardella B, Porru D, Ferdeghini F, Gabellotti EM, Nappi RE, Rovereto B, Spinillo A. Insight into urogynecologic features of women with interstitial cystitis/painful bladder syndrome. Eur Urol 2008;54:1145-1153.

[88] Peters KM, Killinger KA, Carrico DJ, Ibrahim IA, Diokno AC, Graziottin A. Sexual function and sexual distress in women with interstitial cystitis: a case-control study. Urology 2007;70:543-547.

[89] Whitmore K, Siegel JF, Kellogg -Spadt S. SEXUAL

Cystitis/Painful Bladder Syndrome as a Cause of Sexual Pain in Women: A Diagnosis to Consider. J Sex Med 2007;4:720-727.

[90] Vercellini P, Somigliana E, Viganò P, Abbiati A, Barbara G, Fedele L. Chronic pelvic pain in women: etiology, pathogenesis and diagnostic approach. Gynecol Endocrinol 2009;25:149158.

[91] Orr NL, Noga H, Williams C, Allaire C, Bedaiwy MA, Lisonkova S, Smith KB, Yong PJ. Deep Dyspareunia in Endometriosis: Role of the Bladder and Pelvic Floor. J Sex Med 2018;15:1158-1166. 
[92] Nourmoussavi M, Bodmer-Roy S, Mui J, Mawji N, Williams C, Allaire C, Yong PJ.

Bladder base tenderness in the etiology of deep dyspareunia. J Sex Med 2014;11:3078-3084. doi: 10.1111/jsm.12708. PubMed PMID: 25244182.

[93] Yong PJ, Williams C, Yosef A, Wong F, Bedaiwy MA, Lisonkova S, Allaire C. Anatomic sites and associated clinical factors for deep dyspareunia. Sex Med 2017. doi:

10.1016/j.esxm.2017.07.001. PubMed PMID: 28778678.

[94] Reed BD, Sen A, Harlow SD, Haefner HK, Gracely RH. Multimodal Vulvar and Peripheral Sensitivity Among Women With Vulvodynia: A Case-Control Study. J Low Genit Tract Dis 2017;21:78-84.

[95] Welk BK, Teichman JM. Dyspareunia response in patients with interstitial cystitis treated with intravesical lidocaine, bicarbonate, and heparin. Urology 2008;71:67-70.

[96] Salonia A, Zanni G, Nappi RE, Briganti A, Dehò F, Fabbri F, Colombo R, Guazzoni G, Di Girolamo V, Rigatti P. Sexual dysfunction is common in women with lower urinary tract symptoms and urinary incontinence: results of a cross-sectional study. Eur Urol 2004;45:642648.

[97] Laumann EO, Paik A, Rosen RC. Sexual dysfunction in the United States: prevalence and predictors. JAMA 1999;281:537-544.

[98] Lovell RM, Ford AC. Effect of gender on prevalence of irritable bowel syndrome in the community: systematic review and meta-analysis. Am J Gastroenterol 2012;107:991-1000. doi: 10.1038/ajg.2012.131. PubMed PMID: 22613905.

[99] Fass R, Fullerton S, Naliboff B, Hirsh T, Mayer EA. Sexual dysfunction in patients with irritable bowel syndrome and non-ulcer dyspepsia. Digestion 1998;59:79-85. PubMed PMID: 9468103. 
[100] Sobhgol SS, Charndabee SMA. Rate and related factors of dyspareunia in reproductive age women: a cross-sectional study. Int J Impot Res 2007;19:88-94. doi: 10.1038/sj.ijir.3901495. [101] Loftus EV. Clinical epidemiology of inflammatory bowel disease: incidence, prevalence, and environmental influences. Gastroenterology 2004;126:1504-1517. doi: 10.1053/j.gastro.2004.01.063.

[102] O'Connor A, Gracie D, Hamlin J, Selinger C, Ford A. P343 Female gender, somatization and presence of IBS-type symptoms predicts Dyspareunia in patients with IBD. J Crohns Colitis 2017;11:S251-S252. doi: 10.1093/ecco-jcc/jjx002.468.

[103] Kane S. Urogenital Complications of Crohn's Disease. Am J Gastroenterol 2006;101:S640S643. doi: 10.1111/j.1572-0241.2006.00976.x.

[104] Moody G, Probert CS, Srivastava EM, Rhodes J, Mayberry JF. Sexual dysfunction amongst women with Crohn's disease: a hidden problem. Digestion 1992;52:179-183. doi: $10.1159 / 000200951$.

[105] Bambrick M, Fazio VW, Hull TL, Pucel G. Sexual function following restorative proctocolectomy in women. Dis Colon Rectum 1996;39:610-614.

[106] Feagins LA, Kane SV. Caring for Women with Inflammatory Bowel Disease. Gastroenterol Clin North Am 2016;45:303-315. doi: 10.1016/j.gtc.2016.02.007. [107] Barret M, De Parades V, Battistella M, Sokol H, Lemarchand N, Marteau P. Crohn's disease of the vulva. J Crohns Colitis 2014;8:563-570. [108] Yong PJ, Sadownik L, Brotto LA. Concurrent deep-superficial dyspareunia: prevalence, associations, and outcomes in a multidisciplinary vulvodynia program. J Sex Med 2015;12:219227. doi: 10.1111/jsm.12729. PubMed PMID: 25345552. 
[109] McPeak AE, Allaire C, Williams C, Albert A, Lisonkova S, Yong PJ. Pain catastrophizing and pain health-related quality-of-life in endometriosis. Clin J Pain 2018;34:349-356.

[110] Da Luz RA, de Deus JM, Conde DM. Quality of life and associated factors in Brazilian women with chronic pelvic pain. J Pain Res 2018;11:1367.

[111] Leeners B, Hengartner MP, Ajdacic-Gross V, Rossler W, Angst J. Dyspareunia in the Context of Psychopathology, Personality Traits, and Coping Resources: Results From a Prospective Longitudinal Cohort Study From Age 30 to 50. Arch Sex Behav 2015;44:1551-1560. Epub 2015/01/13. doi: 10.1007/s10508-014-0395-y. PubMed PMID: 25573249.

[112] Pitts MK, Ferris JA, Smith AM, Shelley JM, Richters J. Prevalence and correlates of three types of pelvic pain in a nationally representative sample of Australian women. Med J Aust 2008;189:138-142.

[113] Valadares AL, Pinto-Neto AM, Conde DM, Sousa MH, Osis MJ, Costa-Paiva L. A population-based study of dyspareunia in a cohort of middle-aged Brazilian women. Menopause 2008;15:1184-1190.

[114] Basson R. The recurrent pain and sexual sequelae of provoked vestibulodynia: a perpetuating cycle. J Sex Med 2012;9:2077-2092. Epub 2012/06/08. doi: 10.1111/j.17436109.2012.02803.x. PubMed PMID: 22672388.

[115] Dunkley CR, Brotto LA. Psychological Treatments for Provoked Vestibulodynia: Integration of Mindfulness -Based and Cognitive Bel 2016;72:637-650.

[116] Schnatz PF, Whitehurst SK, O'Sullivan DM. Sexual dysfunction, depression, and anxiety among patients of an inner-city menopause clinic. Int J Womens Health 2010;19:1843-1849. 
[117] Yong P, Williams C, Bodmer-Roy S, Ezeigwe C, Zhu S, Arion K, Ambacher K, Yosef A, Wong F, Noga H, Britnell S, Yager H, Bedawiy M, Brotto L, Albert A, Lisonkova S, Allaire C. Prospective cohort of deep dyspareunia in an interdisciplinary setting. J Sex Med, in press. [118] Aredo JV, Heyrana KJ, Karp BI, Shah JP, Stratton P, editors. Relating chronic pelvic pain and endometriosis to signs of sensitization and myofascial pain and dysfunction. Seminars in reproductive medicine; 2017: NIH Public Access.

[119] Mui J, Allaire C, Williams C, Yong PJ. Abdominal Wall Pain in Women With Chronic Pelvic Pain. J Obstet Gynaecol Can 2016;38:154-159. doi: 10.1016/j.jogc.2015.11.003. [120] Fouad LS, Pettit PD, Threadcraft M, Wells A, Micallef A, Chen AH. Trigger Point Injections for Pelvic Floor Myofascial Spasm Refractive to Primary Therapy. J Endometr Pelvic Pain Disord 2017;9:125-130. doi: 10.5301/jeppd.5000283.

[121] Zoorob D, South M, Karram M, Sroga J, Maxwell R, Shah A, Whiteside J. A pilot randomized trial of levator injections versus physical therapy for treatment of pelvic floor myalgia and sexual pain. Int Urogynecol J 2015;26:845-852. doi: 10.1007/s00192-014-2606-4. [122] Pastore EA, Katzman WB. Recognizing Myofascial Pelvic Pain in the Female Patient with Chronic Pelvic Pain. J Obstet Gynecol Neonatal Nurs 2012;41:680-691. doi: 10.1111/j.15526909.2012.01404.x.

[123] Abbott JA, Jarvis SK, Lyons SD, Thomson A, Vancaille TG. Botulinum toxin type A for chronic pain and pelvic floor spasm in women: a randomized controlled trial. Obstet Gynecol 2006;108:915-923. doi: 10.1097/01.AOG.0000237100.29870.cc.

[124] Woolf CJ. Central sensitization: implications for the diagnosis and treatment of pain. Pain 2011;152:S2-S15. 
[125] Brawn J, Morotti M, Zondervan KT, Becker CM, Vincent K. Central changes associated with chronic pelvic pain and endometriosis. Hum Reprod Update 2014;20:737-747.

[126] Nielsen LA, Henriksson KG. Pathophysiological mechanisms in chronic musculoskeletal pain (fibromyalgia): the role of central and peripheral sensitization and pain disinhibition. Best Pract Res Clin Rheumatol 2007;21:465-480.

[127] Malykhina A. Neural mechanisms of pelvic organ cross-sensitization. Neuroscience 2007;149:660-672.

[128] Kaya S, Hermans L, Willems T, Roussel N, Meeus M. Central sensitization in urogynecological chronic pelvic pain: a systematic literature review. Pain Physician 2013;16:291-308.

[129] Terzi H, Terzi R, Kale A. The relationship between fibromyalgia and pressure pain threshold in patients with dyspareunia. Pain Res Manag 2015;20:137-140.

[130] Alappattu MJ, George SZ, Robinson ME, Fillingim RB, Moawad N, LeBrun EW, Bishop MD. Painful intercourse is significantly associated with evoked pain perception and cognitive aspects of pain in women with pelvic pain. J Sex Med 2015;3:14-23.

[131] Zhang Z, Zolnoun DA, Francisco EM, Holden JK, Dennis RG, Tommerdahl M. Altered central sensitization in subgroups of women with vulvodynia. Clin J Pain 2011;27:755.

[132] Hampson JP, Reed BD, Clauw DJ, Bhavsar R, Gracely RH, Haefner HK, Harris RE. Augmented central pain processing in vulvodynia. J Pain 2013;14:579-589.

[133] As-Sanie S, Harris RE, Napadow V, Kim J, Neshewat G, Kairys A, Williams D, Clauw DJ, Schmidt-Wilcke T. Changes in regional gray matter volume in women with chronic pelvic pain: a voxel-based morphometry study. Pain 2012;153:1006-1014. Epub 2012/03/06. doi: 
10.1016/j.pain.2012.01.032. PubMed PMID: 22387096; PubMed Central PMCID:

PMCPMC3613137.

[134] Esenyel M, Caglar N, Aldemir T. Treatment of myofascial pain. Am J Phys Med Rehabil 2000;79:48-52.

[135] Schultz WW, Basson R, Binik Y, Eschenbach D, Wesselmann U, Van Lankveld J.

Women's sexual pain and its management. J Sex Med 2005;2:301-316.

[136] Walsh NE, Schoenfeld L, Ramamurthy S, Hoffman J. Normative model for cold pressor test. Am J Phys Med Rehabil 1989;68:6-11.

[137] Sheffield D, Biles PL, Orom H, Maixner W, Sheps DS. Race and sex differences in cutaneous pain perception. Psychosom Med 2000;62:517-523.

[138] Edwards CL, Fillingim RB, Keefe F. Race, ethnicity and pain. Pain 2001;94:133-137.

[139] Todd KH, Deaton C, D’Adamo AP, Goe L. Ethnicity and analgesic practice. Ann Emerg Med 2000;35:11-16.

[140] Woolf CJ. Pain amplification-A perspective on the how, why, when, and where of central sensitization. J Appl Biobehav Res 2018:e12124.

[141] Johannesson U, de Boussard CN, Jansen GB, Bohm-Starke N. Evidence of diffuse noxious inhibitory controls (DNIC) elicited by cold noxious stimulation in patients with provoked vestibulodynia. Pain 2007;130:31-39.

[142] Varma R, Rollason T, Gupta JK, Maher ER. Endometriosis and the neoplastic process. Reproduction 2004;127:293-304.

[143] Anglesio MS, Papadopoulos N, Ayhan A, Nazeran TM, Noë M, Horlings HM, Lum A, Jones S, Senz J, Seckin T. Cancer-associated mutations in endometriosis without cancer. N Engl J Med 2017;376:1835-1848. 
[144] Burri AV, Cherkas LM, Spector TD. The genetics and epidemiology of female sexual dysfunction: A review. J Sex Med 2009;6:646-657.

[145] Heddini U, Bohm-Starke N, Grönbladh A, Nyberg F, Nilsson KW, Johannesson U. Serotonin receptor gene (5HT-2A) polymorphism is associated with provoked vestibulodynia and comorbid symptoms of pain. J Sex Med 2014;11:3064-3071.

[146] Goldstein AT, Belkin ZR, Krapf JM, Song W, Khera M, Jutrzonka SL, Kim NN, Burrows LJ, Goldstein I. Polymorphisms of the androgen receptor gene and hormonal contraceptive induced provoked vestibulodynia. J Sex Med 2014;11:2764-2771.

[147] Gerber S, Bongiovanni AM, Ledger WJ, Witkin SS. Interleukin-1 $\beta$ gene polymorphism in women with vulvar vestibulitis syndrome. Eur J Obstet Gynecol Reprod Biol 2003;107:74-77. [148] Basson R. Sexual function of women with chronic illness and cancer. Int J Womens Health 2010;6:407-429.

[149] Both S, Brauer M, Weijenborg P, Laan E. Effects of aversive classical conditioning on sexual response in women with dyspareunia and sexually functional controls. J Sex Med 2017;14:687-701.

[150] Mitchell K, Geary R, Graham C, Datta J, Wellings K, Sonnenberg P, Field N, Nunns D, Bancroft J, Jones K. Painful sex (dyspareunia) in women: prevalence and associated factors in a British population probability survey. BJOG 2017;124:1689-1697.

[151] Basson R. Human sex-response cycles. J Sex Marital Ther 2001;27:33-43.

[152] Basson R. Rethinking low sexual desire in women. BJOG 2002;109:357-363.

[153] Sewell M, Churilov L, Mooney S, Ma T, Maher P, Grover SR. Chronic pelvic pain-pain catastrophizing, pelvic pain and quality of life. Scand J Pain 2018. 
[154] Hayes RD, Dennerstein L, Bennett CM, Fairley CK. What is the "true" prevalence of female sexual dysfunctions and does the way we assess these conditions have an impact? J Sex Med 2008;5:777-787.

[155] PUKALL CF, BINIK YM, KHALIFÉ S. A new instrument for pain assessment in vulvar vestibulitis syndrome. J Sex Marital Ther 2004;30:69-78.

[156] Foster DC, Kotok MB, Huang L-S, Watts A, Oakes D, Howard FM, Stodgell CJ, Dworkin $\mathrm{RH}$. The tampon test for vulvodynia treatment outcomes research: reliability, construct validity, and responsiveness. Obstet Gynecol 2009;113:825.

[157] Shum LK, Bedaiwy MA, Allaire C, Williams C, Noga H, Albert A, Lisonkova S, Yong PJ. Deep Dyspareunia and Sexual Quality of Life in Women With Endometriosis. J Sex Med 2018. 


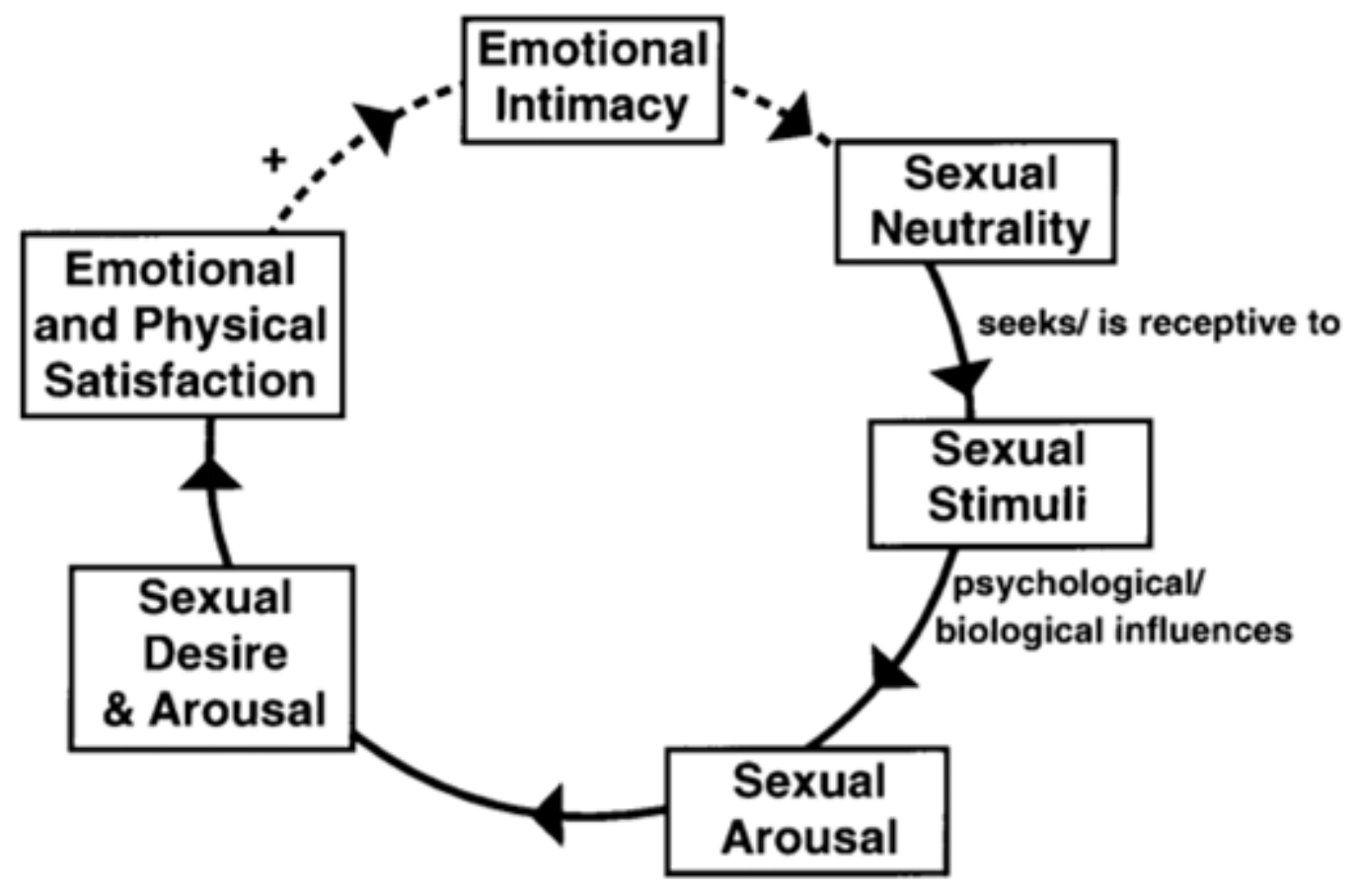

Figure 1. The Basson Female Sexual Response Cycle [151]. Copyright permission obtained from J Sex Marital Ther. 


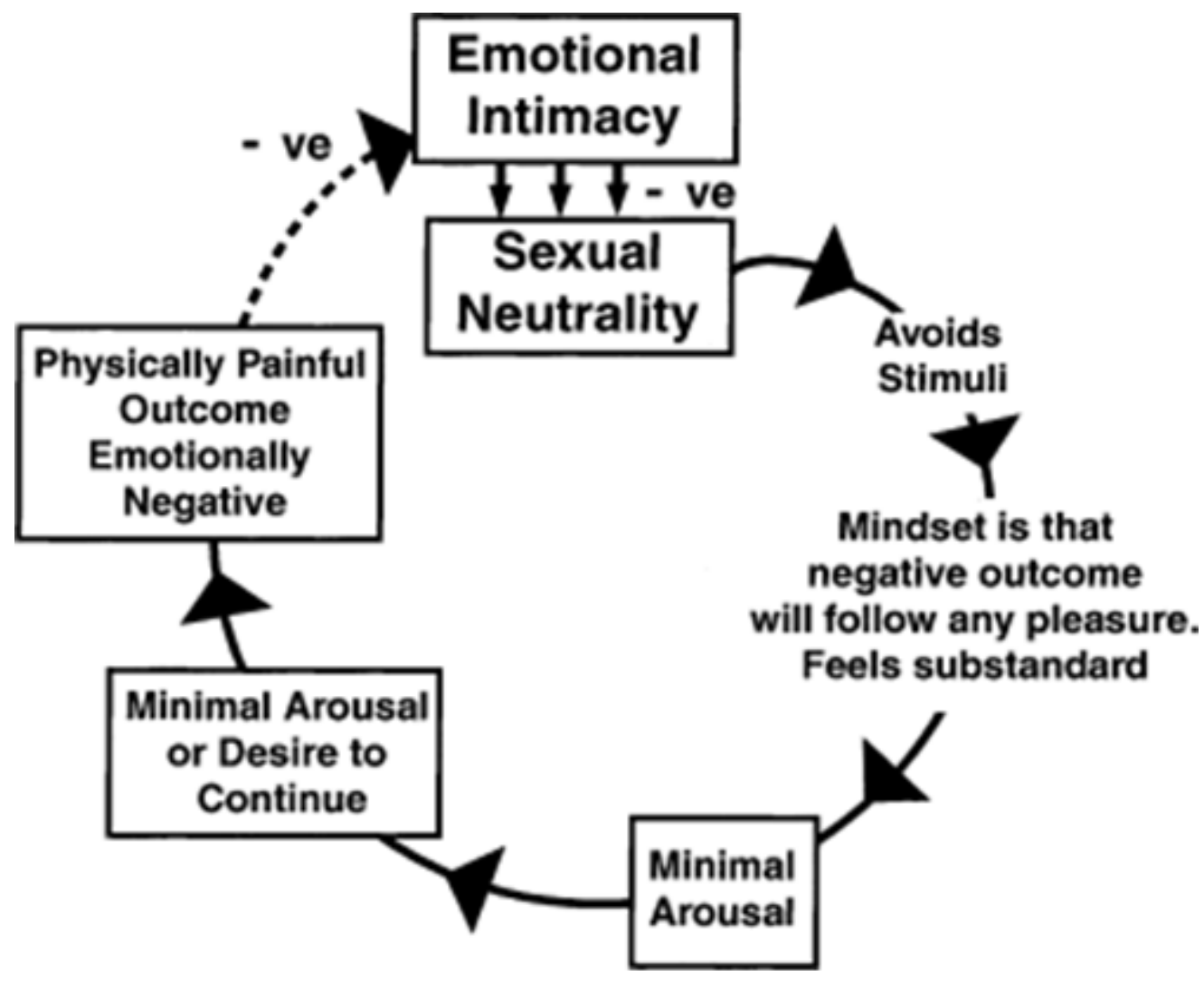

Figure 2. The effect of pain on the female sexual response cycle [152]. Copyright permission obtained from BJOG. 


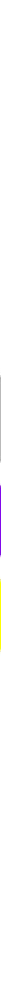

Figure 3. Summary of the types of deep dyspareunia. 